\title{
ĐỀ XUẤT QUY HOẠCH VÙNG TRỒNG NHO ĐẾN NĂM 2030 Ở TỈNH BİNH THUẬN TRÊN CƠ SỞ TÍCH HỘP GIS VÀ AHP
}

\author{
BÙI TH! THANH HƯƠNG \\ Đại học Thủ đô Hà Nội
}

\section{Tóm tắt:}

Cây nho, khá thích ứng với hạn hán và hoang mạc hóa, sẽ là cây trồng chiến lược trong bối cảnh biến đổi khí hậu ở Bình Thuận nên quy hoạch vùng trồng nho trên cơ sở đánh giá thích nghi sinh thái và quy hoạch sử dụng đất của địa phương là một hướng tiếp cận có cơ sở khoa học và thực tiễn. Tích hợp GIS và AHP là phương pháp được lựa chọn để xây dựng bản đồ đánh giá thích nghi sinh thái cho cây nho, dựa vào bản đồ này để xây dựng bản đồ quy hoạch vùng trồng nho đến năm 2030 của tỉnh Bình Thuận. Bài báo giới thiệu phương pháp nghiên cứu tích hợp GIS và AHP để xây dựng bản đồ quy hoạch vùng trồng nho tỉnh Bình Thuận.

\section{1. Đặt vấn đề}

Để thích ứng với điều kiện khô hạn, nhiều loại cây được ưu tiên trồng trọt như: ngô, sắn, mè, đậu tượng, lạc - những loài cây dễ tính, có thể trồng được ở nhiều nơi, phụ thuộc vào hướng chuyển đổi cơ cấu mùa vụ của người dân và chính quyền địa phương; bông - loài cây chịu hạn tốt nhưng hiệu quả kinh tế thấp, thanh long - loại cây trồng đặc sản mang lại nhiều giá trị kinh tế và xã hội lại đã có quy hoạch chi tiết đến năm 2020. Cây nho - một loại cây trồng thích ứng với điều kiện khô nóng, không chỉ là cây xóa đói giảm nghèo mà còn là cây trồng làm giàu và giải quyết công ăn việc làm của người dân địa phương. Theo báo cáo, [4] 1 ha trồng nho có thể cho thu nhập từ 100 - 150 triệu đồng/ năm (bán quả tươi) và giải quyết từ 800 đến 1000 công lao động/ vụ.

Cây nho được du nhập vào Việt Nam từ những năm 1960 - 1970 nhưng được trồng phổ biến ở Bình Thuận bắt đầu từ năm 2000, với quy mô nhỏ ở huyện Tuy Phong. Diện tích trồng nho ở Bình Thuận chiếm $10 \%$ diện tích nho của cả nước, đứng thứ 2 , sau tỉnh Ninh Thuận. Tuy cây nho là loại cây khá thích ứng với điều kiện khô hạn ở tỉnh Bình Thuận, song do sức cạnh tranh trên thị trường kém, đặc biệt hiện nay, mưa nhiều vào cuối thu (thời điểm thu hoạch nho) làm giảm năng suất và sản lượng nho nên người nông dân nơi đây đã chuyển nhiều diện tích trồng nho sang trồng lúa hoặc trồng màu để giải quyết nhu cầu trước mắt. Theo kết quả nghiên cứu biến đổi khí hậu cho Bình Thuận của nhiều nhà khoa học trong và ngoài nước cho thấy, thời gian mùa khô sẽ đến sớm và kết thúc muộn (thời gian mùa khô sẽ kéo dài hơn), lượng mưa mùa khô sẽ giảm nên vấn đề suy giảm năng suất nho do mưa cuối vụ sẽ không còn nhiều. Hơn nữa, nếu thị trường tiêu thụ nho được đảm bảo khi vùng trồng nho ở Bình Thuận liên kết với vùng trồng nho ở Ninh Thuận trong mối liên kết kinh tế sinh thái, diện tích trồng nho ở Bình Thuận sẽ ổn định hơn và được dự báo là cây trồng chiến lược trong bối cảnh biến đổi khí hậu ở tỉnh Bình Thuận. Vì vậy, xây dựng bản đồ qui hoạch trồng nho cho tỉnh Bình Thuận đến năm 2030 mang tính cấp thiết, có ý nghĩa khoa học và thực tiễn cho tỉnh trong giai đoạn hiện nay.

\section{Quy trình nghiên cứu}

Tích hợp GIS và AHP (Analytic Hierachy Process, một phương pháp đánh giá thứ bậc bằng kĩ thuật phân tích đa chỉ tiêu) để thành lập bản đồ quy hoạch vùng trồng nho 
cho tỉnh Bình Thuận đến năm 2030 được thể hiện qua hình 1 dưới đây: (Xem hình 1)

Bước 1: Xác định trọng số cho các chỉ tiêu thích nghi sinh thái cho cây nho bằng phương pháp AHP. Các chỉ tiêu được lựa chọn để phân hạng trong AHP là:

M1: Mưa trung bình năm

M2: Độ ẩm tương đối trung bình năm

M3: Khoảng thời gian mùa khô

M4: Vị trí ít gió bão

M5: Số giờ nắng trung bình năm
M6: Lượng bốc hơi trung bình năm

M7: Độ dày tầng đất

M8: Loại đất

M9: Độ dốc

M10: Độ phì

Để xác định trọng số của các nhân tố thích nghi sinh thái, tác giả nghiên cứu đã sử dụng phương pháp chuyên gia thông qua thiết lập ma trận so sánh cặp giữa các nhân tố đó. Kết quả cụ thể trong bảng 1 dưới đây: (Xem bảng 1)

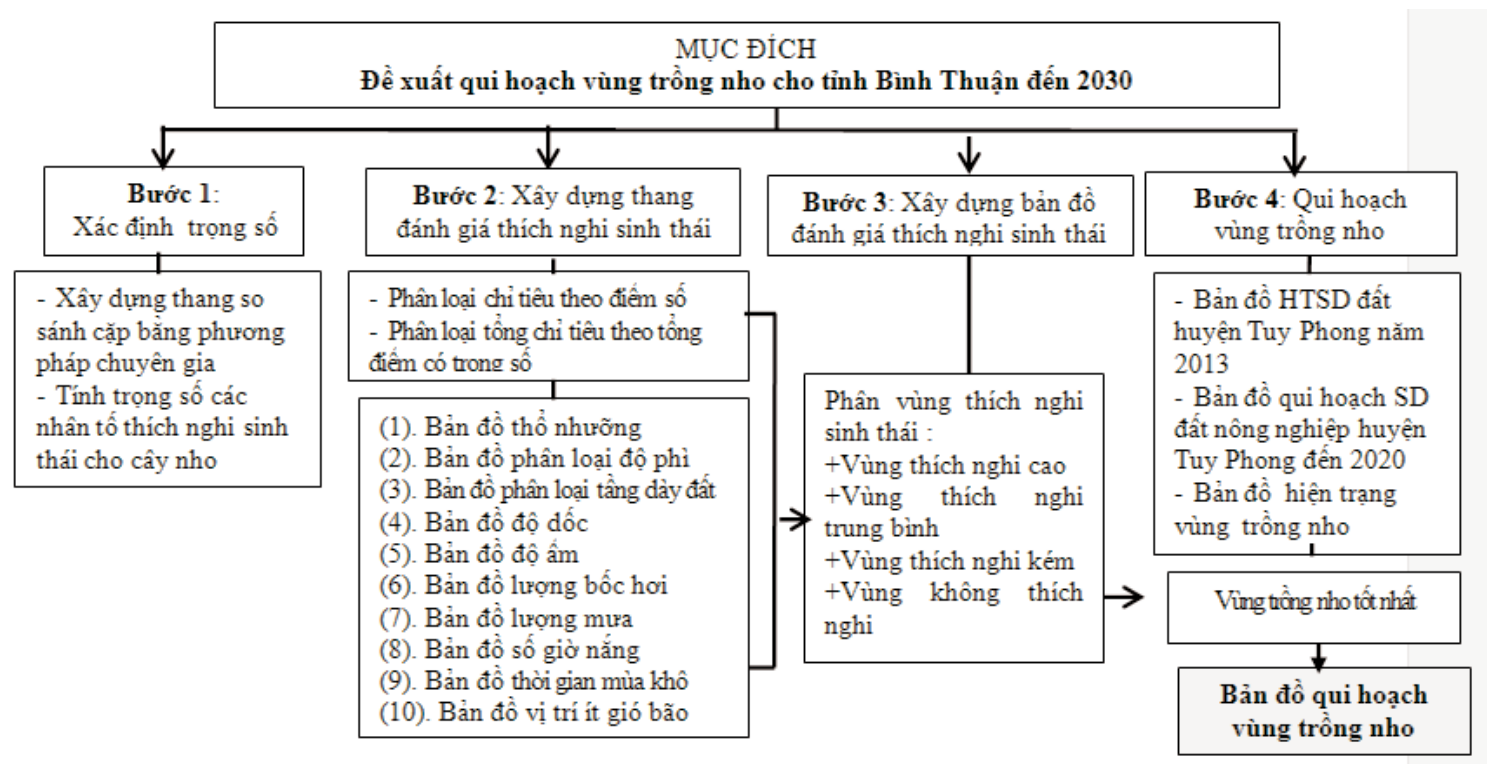

Hình 1: Quy trình đề xuất vùng trồng nho tỉnh Bình Thuận đến năm 2030

Bảng 1: Ma trận so sánh cặp trong nhóm các yếu tố ảnh hưởng đến thích nghi sinh thái của cây nho ở Bình Thuận

\begin{tabular}{|c|c|c|c|c|c|c|c|c|c|c|c|}
\hline & $\mathrm{M} 1$ & $\mathrm{M} 2$ & $\mathrm{M} 3$ & $\mathrm{M} 4$ & $\mathrm{M} 5$ & $\mathrm{M} 6$ & $\mathrm{M} 7$ & $\mathrm{M} 8$ & $\mathrm{M} 9$ & $\mathrm{M} 10$ & Trọng số \\
\hline $\mathrm{M} 1$ & 1 & 0,5 & 0,5 & 2 & 2 & 1 & 2 & 2 & 2 & 2 & 0,12 \\
\hline $\mathrm{M} 2$ & 2 & 1 & 1 & 2 & 2 & 2 & 2 & 3 & 3 & 3 & 0,18 \\
\hline $\mathrm{M} 3$ & 2 & 1 & 1 & 2 & 2 & 2 & 2 & 3 & 3 & 3 & 0,18 \\
\hline $\mathrm{M} 4$ & 0,5 & 0,5 & 0,5 & 1 & 1 & 1 & 1 & 2 & 2 & 2 & 0,09 \\
\hline $\mathrm{M} 5$ & 0,5 & 0,5 & 0,5 & 1 & 1 & 0,5 & 2 & 2 & 2 & 2 & 0,09 \\
\hline M6 & 1 & 0,5 & 0,5 & 1 & 2 & 1 & 2 & 2 & 2 & 2 & 0,11 \\
\hline M7 & 0,5 & 0,5 & 0,5 & 1 & 0,5 & 0,5 & 1 & 2 & 2 & 2 & 0,08 \\
\hline M8 & 0,5 & 0,33 & 0,33 & 0,5 & 0,5 & 0,5 & 0,5 & 1 & 1 & 1 & 0,05 \\
\hline M9 & 0,5 & 0,33 & 0,33 & 0,5 & 0,5 & 0,5 & 0,5 & 1 & 1 & 1 & 0,05 \\
\hline M10 & 0,5 & 0,33 & 0,33 & 0,5 & 0,5 & 0,5 & 0,5 & 1 & 1 & 1 & 0,05 \\
\hline
\end{tabular}


Bước 2: Xây dựng thang đánh giá thích nghi sinh thái cho cây nho dựa trên phân loại tổng điểm thích nghi (công thức 1).

$$
Y=\sum_{i=0}^{n} M_{i} W_{i}
$$

Trong đó: $Y$ : chỉ số thích nghi, $M_{i}$ : điểm thích nghi của nhân tố i, $W_{i}$ : trọng số của nhân tố $i$. Vì tỷ số nhất quán từ ma trận so sánh cặp (bảng 1) $C R=0,0151 \quad(C R<0,1)$ nên các trọng số này được chấp nhận, ta có phương trình đánh giá thích nghi sinh thái tổng quát là (công thức (2)):

$$
\begin{aligned}
& Y=0,12 M 1+0,18 M 2+0,18 M 3+0,09 M 4+0,09 M 5+ \\
& +0,11 M 6+0,08 M 7+0,05 M 8+0,05 M 9+0,05 M 10
\end{aligned}
$$

Bước 3: Xây dựng bản đồ đánh giá thích nghi sinh thái cho cây nho tỷ lệ 1:800.000 (hình 2) trên cơ sở dữ liệu của 10 bản đồ: thổ nhưỡng, phân loại độ phì, độ dốc, độ dày tầng đất, độ ẩm tương đối, lượng mưa trung bình năm, số giờ nắng trong năm, thời gian mùa khô, vị trí ít gió, bão. Cơ sở phân loại đánh giá thích nghi sinh thái như sau:

- Vùng thích nghi cao $\quad: Y=8 \div 10$

- Vùng thích nghi trung bình : $Y=6 \div 8$

- Vùng thích nghi kém $\quad: Y=4 \div 6$

- Vùng không thích nghi $: Y<4$

(Xem hình 2)

Bước 4: Xây dựng bản đồ quy hoạch vùng trồng nho cho tỉnh Bình Thuận tỷ lệ 1:50.000 trên cơ sở các bản đồ: đánh giá thích nghi sinh thái cho cây nho, hiện trạng phân bố các vùng trồng nho ở tỉnh Bình Thuận, bản đồ hiện trạng sử dụng đất huyện Tuy Phong (địa phương có phần lãnh thổ thuộc vùng thích nghi cao cho cây nho), bản đồ quy hoạch sử dụng đất huyện Tuy Phong. Kết quả của phương pháp này được trình bày cụ thể ở hình 3: (Xem hình 3)

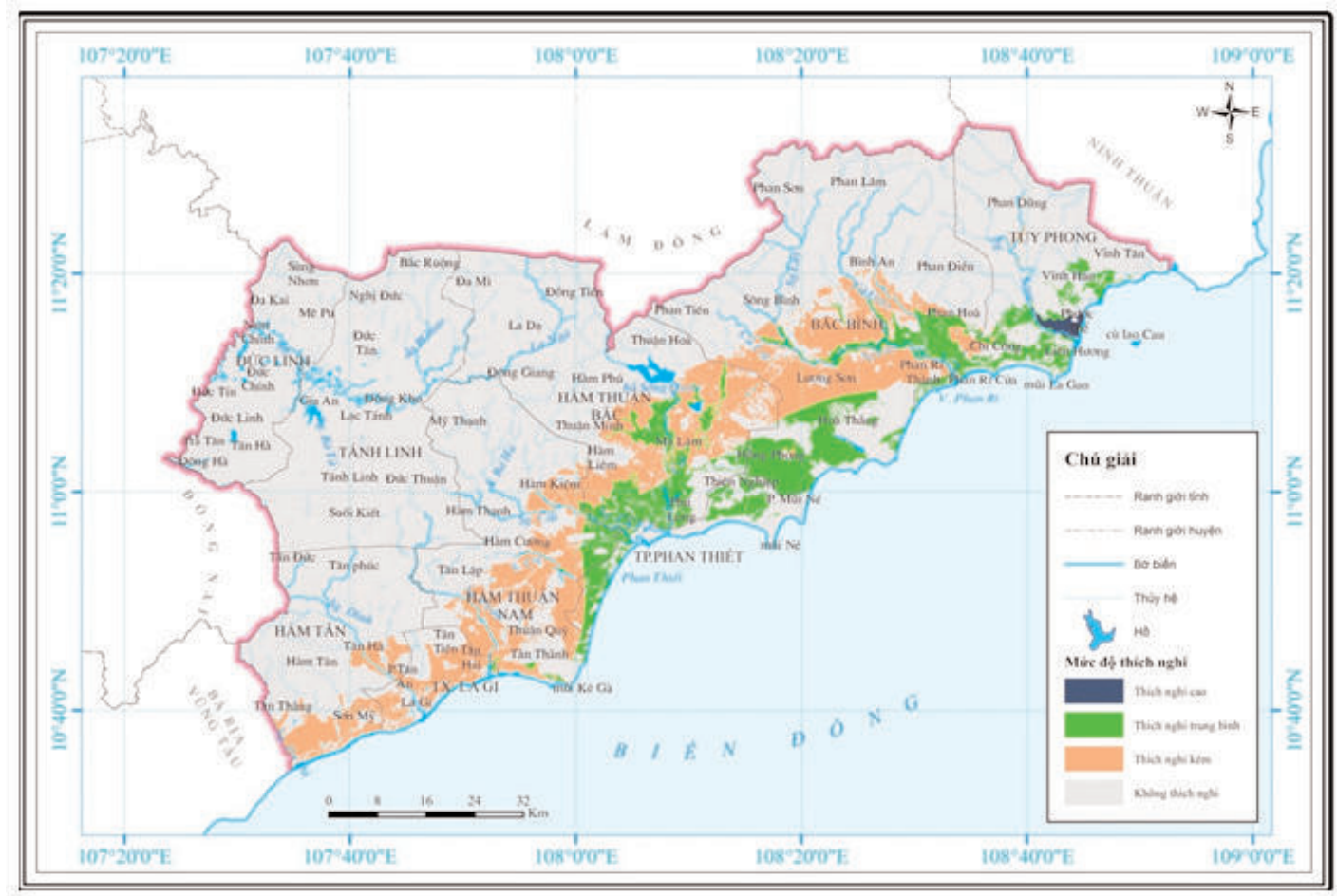

Hình 2: Bản đồ đánh giá thích nghi sinh thái cho cây nho ở tỉnh Bình Thuận 


\section{Kết quả và thảo luận}

Theo kết quả thu được từ bản đồ đánh giá thích nghi sinh thái (hình 2), vùng thích nghi cao có diện tích 1639,32 ha phân bố ở hạ lưu sông Lòng Sông thuộc địa bàn 2 xã Phước Thể, Phú Lạc của huyện Tuy Phong. Đây là khu vực đất phù sa có khả năng tiêu thoát nước tốt, độ phì ở mức độ tương đối và điều kiện thời tiết phù hợp cho cây nho sinh trưởng, phát triển (lượng mưa trung bình năm thấp, độ ẩm trung bình năm thấp, lượng bốc hơi cao và thời gian mùa khô kéo dài, ít chịu ảnh hưởng của mưa bão vào thời điểm thu hoạch nho). Vùng thích nghi trung bình có diện tích 60399,55 ha phân bố khá rộng, ven các con sông hoặc vùng duyên hai ven biển, thuộc địa bàn các huyện Tuy Phong, Bắc Bình, TP Phan Thiết, Hàm Thuận Nam, Hàm Thuận Bắc. Nho trồng ở vùng thích nghi trung bình có thể cho năng suất cao nếu có sự can thiệp về giống và kĩ thuật điều chỉnh thời gian thu hoạch phù hợp với điều kiện tự nhiên của khu vực này.

Trên cơ sở chồng lớp thích nghi sinh thái tốt nhất của cây nho lên bản đồ quy hoạch sử dụng đất của tỉnh Bình Thuận, tác giả đã lựa chọn được vùng trồng nho cho tỉnh Bình Thuận (hình 3) thuộc địa bàn xã Phú Lạc và Phước Thể huyện Tuy Phong. Qua bản đồ qui hoạch sử dụng đất huyện Tuy Phong cho thấy, phần lớn diện tích của 2 xã được quy hoạch trồng lúa. Vùng đất trồng cây ăn quả lâu năm, cây hàng năm có diện tích không lớn và phân bố rải rác trên địa bàn của 2 xã. Diện tích nuôi trồng thủy sản (nước ngọt và nước lợ) nằm ở khu vực ven biển xã Phước Thể, chiếm một nửa diện tích toàn xã. Diện tích đất chưa sử dụng và đất ở không nhiều nên loại hình sử dụng đất chủ yếu ở khu vực nghiên cứu là đất SXNN. (Xem bảng 2)

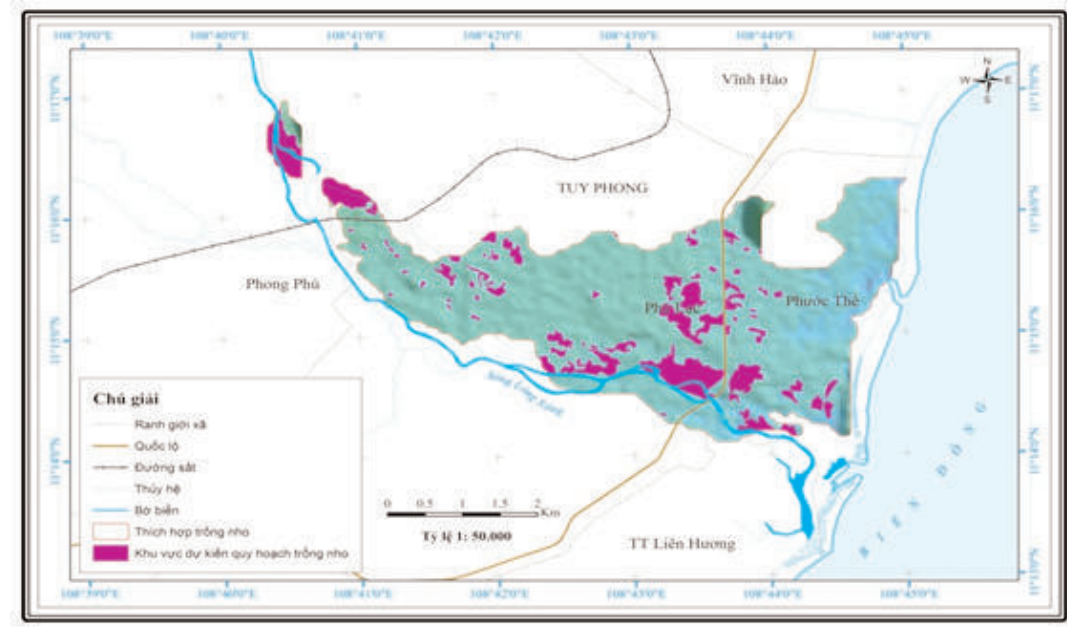

Hình 3: Bản đồ đề xuất vùng trồng nho đến năm 2030 cho tỉnh Bình Thuận

Bảng 2: Đề xuất chuyển đổi một số loại hình sử dụng đất sang trồng nho ở xã Phú Lạc, Phước Thể, huyện Tuy Phong (Thống kê từ hình 3)

\begin{tabular}{|c|l|c|c|}
\hline STT & \multicolumn{1}{|c|}{ Loại đất } & Ký hiệu & Diện tích (ha) \\
\hline 1 & Đất trồng cây hàng năm khác & BHK & 48,41 \\
\hline 2 & Đất trồng cây công nghiệp lâu năm & LNC & 23,02 \\
\hline 3 & Đất trồng cây năm quả lâu năm & LNQ & 155,86 \\
\hline & Tồng & & $\mathbf{2 2 7 , 2 8}$ \\
\hline
\end{tabular}


Hiện tại, xã Phú Lạc có hơn 40 ha trồng nho ven khu vực sông Lòng Sông và xã Phước Thể có khoảng gần 10 ha. Tác giả đề xuất đến năm 2030, diện tích trồng nho có thể mở rộng thêm gấp 4 đến 5 lần diện tích trồng nho hiện tại (khoảng 227, 28 ha) từ những khu vực SXNN kém hiệu quả nhu: từ vùng đất trồng ngô, trồng lạc (khoảng 48,41 ha), từ vùng đất trồng điều (23,02 ha), từ vùng đất trồng xoài, nhãn, me $(155,86$ ha) (bảng 2). Hầu hết những khu vực trồng nho này đều là những nơi có cơ sở hạ tầng ổn định như: giao thông thuận lợi, hệ thống thủy lợi khá, hệ thống điện nước tốt.

\section{Kết luận}

Bằng cách tích hợp GIS, AHP, bản đồ đánh giá thích nghi sinh thái cho cây nho ở tỉnh Bình Thuận đã được thành lập với 4 cấp độ đánh giá thích nghi: thích nghi cao, thích nghi trung bình, thích nghi kém và không thích nghi. Trong điều kiện thực tiễn và trong bối cảnh biến đổi khí hậu, đến năm 2030, vùng trồng nho tốt được đề xuất mở rộng thêm khoảng 227,28 ha, tại hai xã Phước Thể, Liên Hương huyện Tuy Phong, trên cơ sở chuyển đổi từ vùng đất trồng kém hiệu quả (đất trồng cây ăn quả, cây công nghiệp lâu năm, cây hàng năm) thành những trang trại trồng nho, có đầu tư thâm canh sâu gắn với ổn định thị trường tiêu thụ. Những vùng này sẽ được liên kết với vùng trồng nho Ninh Thuận tạo thành vùng chuyên canh nho, không chỉ là vùng nguyên liệu tập trung mà sẽ là vùng du lịch sinh thái nổi tiếng trong khu vực và trên thế giới. $\bigcirc$

\section{Tài liệu tham khảo}

[1]. Vũ Quốc Tuấn, Nguyễn Kim Lợi, (2013), Tích hợp GIS và AHP trong đánh giá thích nghi cây trồng tại huyện Di Linh tỉnh Lâm Đồng, Hội thảo GIS toàn quốc năm 2013.

[2]. Phạm Quang Vinh và nnk (2012), Đánh giá tác động của biến đổi khí hậu toàn cầu và hoang mạc hóa đến môi trường và xã hội ở khu vực Nam Trung Bộ, Đề tài Nghị định thư Việt-Bỉ, 2010-2011.

[3]. Thomas L. Saaty (1990), "How to make decision: The Analytic Hierarchy process", European Journal of Operational Research 48(1990) 9-26 North Holland.

[4]. Sở khoa học và công nghệ Ninh Thuận (2014), Kỷ yếu hội thảo khoa học "Định hướng phát triển cây nho và vang Ninh Thuận".

\section{Summary}

\section{Planning the grape area in 2030 in Binh Thuan province base on integrating GIS and AHP}

\section{Bui Thi Thanh Huong \\ Hanoi Capital University}

Grape tree, quite suitable to drought and desertification, will be the special tree in term climate change in Binh Thuan province and so planning the grape area base on assessing adaptation of grape and land use planning is scientific and practical approach. The article introduced the method of integration GIS and AHP to build the map of planning the grape area for Binh Thuan province. $\mathrm{O}$

Ngày nhận bài: 04/02/2015. 